\title{
Future Development and Present Situation of China's Luxury Market
}

\author{
Shanshan Lin \\ Ningbo Dahongying University \\ NingBo, China \\ corallin33@hotmail.com
}

\author{
Xiaochun Shi \\ Ningbo Dahongying University \\ NingBo, China
}

\begin{abstract}
Chinese tourists have become one of the groups that consume most luxury goods in the world since 2013. Based on the data from ministry of commerce of the People's Republic of China, the foreign luxury goods consumption of Chinese tourists is about 1.02 trillion Yuan in 2015. Meanwhile, Chinese luxury goods market exhibits a potential of stronger demand and it has attracted a lot of international companies to pay more attention to Chinese market. In this article, the facts and characteristics of China's luxury market will be discussed; and some strategies are suggested for both foreign and local companies with regard to possible development.
\end{abstract}

Keywords-luxury goods; local brand; second tier cities; China luxury market

\section{INTRODUCTION}

China is growing fast during the last 15 years, and is still one of the fastest growing countries in the world, with one sixth of population living in this country. China shows large potential in any kind of consumption, not just luxury goods. Starting from 1990s, luxury brands entered Chinese market and with the booming of Chinese economy, luxury consumption is growing fast at the early 2000s, and it didn't even slow down during the last two global financial crises at 2004 and 2008[1]. It reached its peak at 2013 with slight slowdown afterwards, due to both the global economic crisis and anti-corruption campaign in China. However, China still consists $46 \%$ percent of global luxury consumption. With large potential, China still shares a relatively high price compared to most countries, and large amount of consumptions are made overseas. With relatively younger and less wealthy consumer population, China might need a different strategy compared to other major luxury markets.

\section{ECONOMICS}

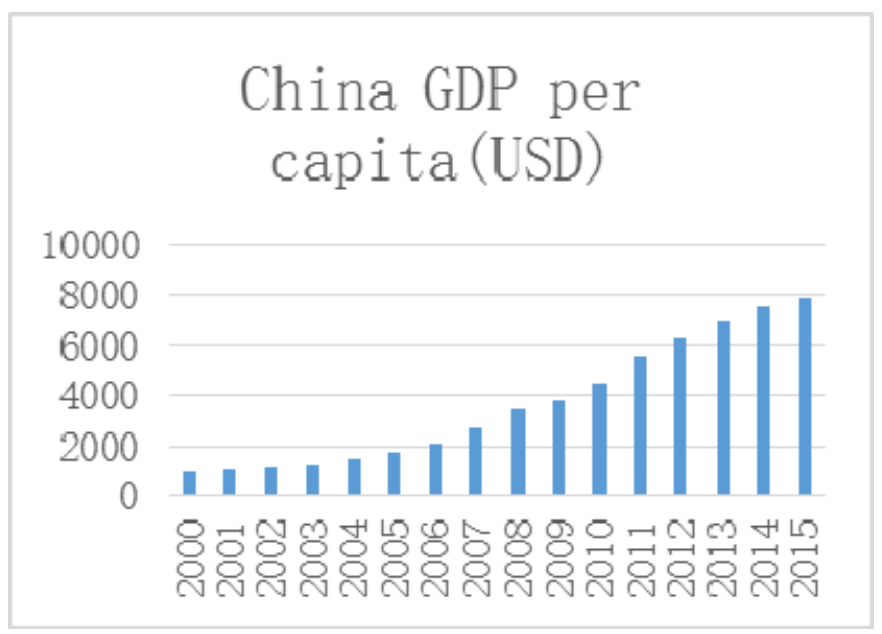

Fig. 1. China GDP per capita (USD)

As shown in the graph, China has nearly 8 times the GDP per capital as it is at 2000, which is only 15 years ago, that is an annual growth of about $15 \%$. With the law of diminishing return, China has slowed down from its fast growth, and is now experiencing a steady but still relatively fast speed of growth economically.

However, with high growth in economy, China shares a common issue with all developing countries that the gap between poor and rich is large compare to developed country. As mentioned in Credit Suisse Global Wealth Data book, China has increased 3 times of its middle-class population compared to America, while the upper middle-class population still only consists of less than $3 \%$ of the whole population compared to the enormous $40 \%$ in North America [2]. China as the best developing country is walking through an age that should focus on easing the poor-rich gap rather than the number in economic growth. Although China is experiencing a slowdown in economy, the growth of upper middle-class population will be the next possible catalyzer to stimulate the luxury market in China.

\section{MARKET CHARACTERISTICS}

There are two main characteristics of Chinese luxury market: low age and less wealthy. According to Bomoda's 2015 China Luxury Blueprint, in China, luxury good 
consumers have an average age of 33.1 years old and $80 \%$ of them are between ages of 25 to 44, and shares an average income of $\$ 83,361$ compared to $\$ 99,364$ in USA [3]

With luxury goods becoming popular in China, they become a symbol of luxurious life style. Chinese culture has its nature of showing off and herd instinct, and these affects the younger generation the most-buying luxuries even became a very important part of their life. As per statistics, Chinese shows a relatively low age of luxury goods consumption. With China's booming economy, lots of people became suddenly rich. However, they were poor during early years of their lives and they are usually uneducated. Thus they tend to give their younger generation a 'better life' without considering whether it is good for them. These younger generation are being called the second generation rich. These people are rich without spiritual pursuit. Luxury goods are a way to show their wealth and they wanted to be spotted. And there are some young people that are not that wealthy, but looking forward to having a luxurious style of living. They are willing to save money for some luxury goods, they are not only symbols of fashion and taste, and on the other hand they are reflection of people's willingness to pursue luxurious style of living.

Furthermore, with high density populated, people are paying more attention on how their own impression is from others. This also helps the phycology of comparing with other and showing off, luxury good is a symbol of rich. Also, the irrationality of herd instinct, buying goods that has 'investing value', use what celebrities use. China still needs time to digest the harvest from fast growing economy and get to know better about luxuries, to be rational on luxury consumption.

With the characteristics of Chinese market, it shows some trends of Chinese market. Peoples tend to buy entry level luxury good. According to Bain's statistics, in 2015, brands like Coach and Michael Kors opened the most stores in China while the whole luxury business is shrinking due to the global economy slowdown. In addition, a lot more outlet stores are opened in China during 2015. Outlet stores are malls that people can buy out of seasoned goods for a discount, which also means that people are willing to buy luxury goods with a lower price. However, the richest people are now aware of the low-profile style of living, with the use of personalized designer clothes for chairman's wife; richest people are now paying more attention to the design of luxury goods rather than just a logo. Personalized products without $\operatorname{logo}$ are also becoming popular in China.

\section{The DeVElopment OF SECOND TIER CITIES}

With Chinese market becoming mature, the first tier cities are becoming fulfilled; second tier cities are now emerging. From the ability side, price of housing is booming in the last few years. According to survey, housing price in first tier cities doubled every 18 months, although with higher income, with traditional Chinese concept of buying property [4], people from first tier are struggling with housing. This indeed limited their ability to buy luxury goods; while on the other hand, people from second tier cities have relatively high income but not suffer too much from housing price, digging into the large potential of second tier cities will lead the market to new high growth phase.

However, although luxury market has been growing so fast in China for the last two decades, it is a pity that there are few Chinese brands that show on this fast track of luxury goods market. There are two reasons that might explain this situation. First, the impact of 'made in China', not only for foreign consumers, but also for our local consumers, made in China means cheap and low quality. It is easy to observe that people are purchasing almost everything from overseas. Because of this, it is hard for local brands to have a high selling price. Without high price, high quality and designs cannot be applied to products; it is a barrier for local brands. Second, with the traditional education and culture being moderate, not much creativity in normal Chinese people, it is hard to have a designer or artist with world class creativity, also with the local market depressing they are hard to show their talent, the trend forced them to find opportunity in other more matured countries in luxury industry.

\section{Government Policy Change: Anti-Corruption, TaX} REDUCTION, FreE TRADE ZONE

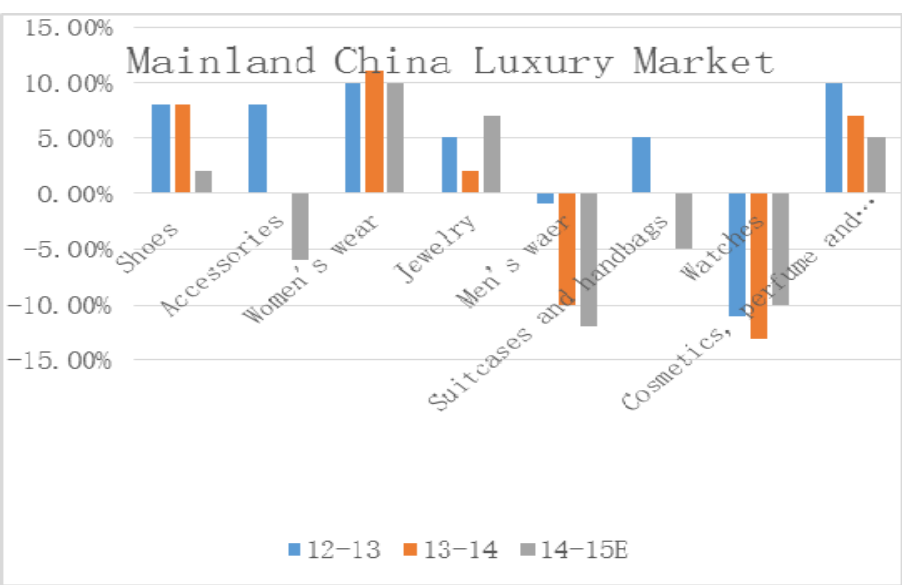

Fig. 2. Sources: Bain survey of luxury goods consumers in mainland China

Starting from 2012, Chinese government is imposing anticorruption campaign which obviously has influenced luxury consumption. Brands that were focusing on man wear are affected the most, with support of data, sales decreased at a rate over $10 \%$ during the past two years on this category, and it is the only category start and depending its decline from 2012, while with global economy slow down, some other category starts to decline or slow down its increasing pace from 2014 [5]. 


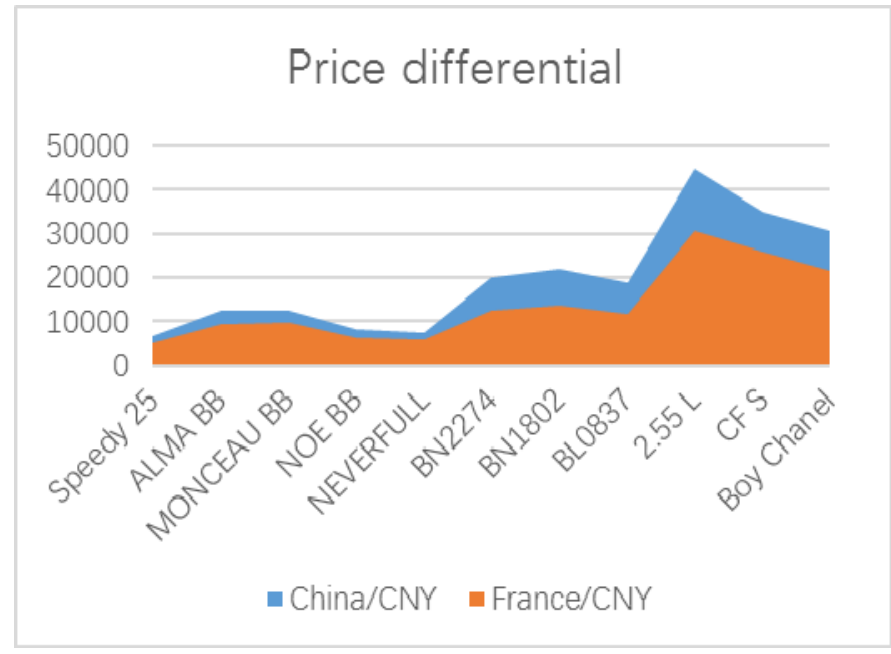

Fig. 3. Price differential between China and France for some typical luxury handbags

Tariff on luxury goods is reduced as well with the new taxation policy on imported luxury goods. In addition, more and more free trade zones are built from 2013, the purpose of building these free trade zones are to gradually change China from a high import tax country to low tariff country, which on the other hand support the agreement with WTO to reduce import tax. Reduction on the import tax will eventually ease the huge price gap between China and countries like European and North American countries. Lower price in China will also bring the amount of consumption abroad back to local market, and make luxuries more affordable for lower income people.

\section{STRATEGIES}

\section{A. Consumer Demand}

Having a considered the overall situation of Chinese market and its characteristic, it requires strategic changes among brands in order to share a higher percentage of Chinese market. As China currently has large gap between poor and rich, more focus on both end of the product line is the better strategy, entry level to attract the relatively low income customers and the high-end customized products to keep the top customers. As well as opening more outlet stores, stores with luxurious shopping experience and top of brand products should be opened in upscale malls. Also, with the effect of anticorruption campaign, categories like man's wear is going through large decline, brands and groups should be focusing on other categories. In addition, with China's declining taxation policy on importing luxuries, diminishing tax on importing luxuries is foreseeable, small sacrifice in profit to ease the price gap between China and other countries may help to grab market share before tax is cut to a very low level.

\section{B. Corporation}

According to the unique characteristics of Chinese market, cooperation with local designer to have designs with more Chinese elements, and use local younger generation celebrities as endorser to show a localized and popular within young people brand image to win the relatively young market in China.
On the industrial side of view, as the issue of 'made in China', both government and the local industry have paid attention to changing the view. In the recent years, it is not hard to find that cheaper, solely labor based products are made in China, while more technical, luxury goods are not made in China, a lot 'made in China' can be seen on tags of luxury goods, the quality of production are improving, the next step can be focusing on developing local designs[6].

On the other hand, cooperate with TV programs to find the possible future designers will not only advertise on the new image of 'made in China' quality and design, but also give the local talented designer a platform to show what they can do [7]. Also, cooperate with global luxury brands to have more localized design, which will also help the global brand an opportunity to show its value in Chinese market and give local designers a way to learn how the industrial leaders work. For example, the design of Chinese zodiac from Vacheron Constantin, these marketing strategies made a good response. Lack of depth in local cultural understanding is their short board, while popularity is ours; it is a good opportunity to cooperate.

\section{CONCLUSION}

With the rapid development of Chinese economy, luxury consumption seems to become a popular trend, and middleclass consumption has become the most important potential consumer group in the luxury market. Through the analysis of the luxury goods market in our country at present, we can find that:

Firstly, China's luxury market still has a huge development space. And this huge growth potential will attract more luxury brands to enter the Chinese market. At the same time, these luxury brand enterprises have to adjust its marketing strategies to expand the market. As well, Chinese domestic luxury brands should still look for a suitable development path, and continue to move closer to the world's top luxury brands.

Secondly, the Chinese luxury consumers tend to be mature. The purchase of luxury goods is no longer blindly worshiping the brand, and will consider the design of the brand and cultural connotation, rational treatment of luxury goods.

Finally, the sales channels will be more diversified. At the same time, China's luxury market also showed more intense competition in the market in the future, with the result that the enterprises should focus on improving brand awareness, local luxury goods development, consumers tend to be younger and luxury goods import tariffs and other trends.

\section{REFERENCES}

[1] Chenkao Zhang,Twenty-first Century marketing mix of innovative thinking based on $4 \mathrm{R}$ marketing mix theory [J] Industrial technological economy,2004(13):89-90 (in Chinese)

[2] Di Deng,Research on the development potential of luxury market in second tier cities in China,[J] Commercial economy,2011(22):14-15(in Chinese)

[3] Jianqiu $\mathrm{Wu}$, Xiaofen $\mathrm{Ji}$, The transition period of China's luxury market[J] management and Administration,2014(11):28-30(in Chinese) 
[4] Bain company,2015 China Luxury Market trends: Can it rebound? , www.bain.com.cn, 2016

[5] Credit Suisse, Minimum wealth of middle class, 2015, selected countries, Global Wealth Databook 2015

[6] Tom Doctoroff, What Chinese want: culture,communism and china's modern consumer[M].London: Palgrave Macmillan trade, 2012
[7] Mijeong Kim, Sookhyun Kim, The Effect of distribution foreign luxury channel diversification foreign luxury fashion brands on consumer' brand value and loyalty in the Korean market,[J] Retailing and Consumer Service, 2010 